The fanzines, publications of fans, directed at other fans of a certain artistic expression, have achieved a great progress in recent years, thanks in part to advance technological, but also by the maturity of the public and authors, encouraged by the fanzines. As a vehicle for groups that produce the fringes of the cultural industry, the fanzines can be considered as an event that falls within the field of study of folkcomunicação. The wealth of fanzines is in the testing of artistic languages and encouraging the production and delivery of new authors.

Keywords: Fanzine, comics, communication 


\title{
Fanzine: comunicação popular e resistência cultural
}

\author{
Henrique \\ MAGALHÃES
}

Os fanzines, publicações de fãs, ou aficionados, dirigidas a outros fãs de determinada expressão artística, têm alcançado uma evolução enorme nos últimos anos, em parte graças ao avanço tecnológico, mas também pelo amadurecimento do público e autores, fomentados pelos próprios fanzines. Como veículo de grupos que produzem à margem da indústria cultural, os fanzines podem ser considerados como uma manifestação que se insere no campo de estudo da folkcomunicação. A riqueza dos fanzines está na experimentação de linguagens artísticas e no fomento à produção e veiculação dos novos autores.

Palavras-chave: Fanzine, quadrinhos, comunicação 
Publicações amadoras produzidas por fãs e dirigida a fãs de expressões artísticas, os fanzines surgiram nos Estados Unidos na década de 1930 com os autores de ficção científica. Esse tipo de revista artesanal ou semiprofissional representava a única possibilidade para os jovens autores veicularem seus trabalhos, que se tratavam de um gênero ainda considerado como subliteratura. Foi com esse caráter de resistência e inovação que os fanzines se firmaram e se difundiram pelo mundo. De pequenas revistas baratas que serviram de suporte a experimentações artísticas, os fanzines se transformaram em publicações reflexivas, analisando os diversos aspectos das artes de forma crítica e independente.

No Brasil os fanzines surgiram em outubro de 1965, sendo, então, chamados de boletins. O primeiro fanzine brasileiro foi editado em Piracicaba, São Paulo, por Edson Rontani, chamouse Boletim Cincia-Fico Alex Raymond e era dedicado às histórias em quadrinhos. Foi só em meados da década de 1970 que se começou a utilizar o termo "fanzine", quando essa denominação passou a ser difundida de forma mais freqüente pelas revistas especializadas francesas e pelas publicações ligadas ao movimento punk inglês.

O caráter de "marginalidade", por serem publicações produzidas à margem do mercado, sem fins lucrativos e com forte motivação comunitária, habilita os fanzines a se inserir na categoria de folkcomunicação, pois são porta-vozes de setores e expressões artísticas menosprezadas pela grande imprensa. Os fanzines representam o pensamento de indivíduos, associações e grupos de aficionados que produzem seus próprios veículos como forma de interação, troca de informações e opiniões.

No tocante aos fanzines dedicados aos quadrinhos, que formam uma das mais representantes vertentes desse gênero de publicações no país, eles representam a resistência dos autores frente ao descaso das editoras, a afirmação dos quadrinhos locais e contraposição aos quadrinhos estrangeiros. Nesse contexto, a importância dos fanzines reside não só na difusão e renovação dos quadrinhos no Brasil, mas também por contribuírem para a criação de um espaço essencial de discussão e avaliação dos quadrinhos como expressão artística. 
Inicialmente os fanzines não passavam de boletins rudimentares, impressos em mimeógrafos. Com o desenvolvimento tecnológico das últimas décadas do século 20, o barateamento e popularização dos meios de impressão, foram surgindo fanzines cada vez mais sofisticados, aproximando-se do acabamento e requinte gráfico das publicações do mercado.

\section{Os fanzines e a folkcomunicação}

Como boletins produzidos por indivíduos, fã-clubes ou associações, os fanzines (de fanatic magazine, ou magazine do fã), são publicações amadoras, sem fins lucrativos, que visam a troca de idéias, investigação ou promoção de um objeto de culto. A frágil estrutura dos fanzines, que se caracteriza por pequenas tiragens, difusão restrita para um público dirigido e temática especializada, condiciona sua concepção gráfica, seu alcance e sua periodicidade. Esse tipo de publicação destina-se a um público interessado e que já tem alguma referência sobre o assunto enfocado, ou seja, ao fã.

O termo "fã", mesmo estando na etimologia da palavra fanzine, talvez não represente de forma precisa os editores dessas publicações. Fruto de uma ação entusiasta de simpatizantes de determinada atividade artística, seus protagonistas poderiam ser mais considerados como aficionados. Mais que uma postura de passividade e contemplação do objeto de culto, própria do fã, o que caracteriza o editor de fanzine é sua atitude proativa, sua necessidade de interação e investigação.

Numa referência ao culto dos astros da indústria cultural, Edgar Morin (1972) atribui ao fã uma adoração quase religiosa. Para ele, o amor do fã não pode possuir, seja no sentido sociológico ou no senso físico do termo. A estrela escapa à apropriação privada. O amor pela estrela não tem ciúmes, é sem desejo, é compartilhado, pouco sexualizado, o que quer dizer, é um amor de veneração.

Em seu anonimato, o fã se resigna a reunir todas as coisas que representem a materialização do objeto amado, como se 
dele pudesse se apropriar pelo consumismo. Para Morin, o fã desejaria ser amado, mas com humildade. "É esta desigualdade que caracteriza o amor religioso, adoração não recíproca, mas eventualmente recompensada" (Morin, 1972, p.69).

Podemos pensar numa dessas recompensas como o acesso à vida privada do mito graças às informações publicadas pelas revistas profissionais. A impossibilidade do contato direto de forma permanente com o ídolo leva o fã a participar de um fãclube, cuja direção pode chegar a manter relações de proximidade com o objeto de culto.

Já para o editor de fanzine, não basta essa atitude contemplativa, de veneração. Ele quer algo mais que um certo conhecimento sobre o assunto enfocado. O caráter desse tipo aficionado requer, em princípio, uma motivação impregnada de inquietude, uma curiosidade sobre os bastidores da arte. Para o editor de fanzine, mais que ser fã, é preciso deixar-se levar pelo desejo de participar ativamente do meio que é objeto de admiração e estar disposto a interferir, usando para isso a produção dessas pequenas publicações.

No campo das artes, não há limite temático para os editores de fanzines. Alguns se dedicam às estrelas da música pop, aos ídolos do rock, às bandas do momento, a um gênero musical; outros procuram investigar os astros do cinema e os gêneros cinematográficos. Literatura, televisão, comportamento, moda, rádio, tudo o que estiver ligado a expressões artísticas e à indústria cultural pode ser objeto de estudo dos fanzines.

Mas, sem dúvida, os quadrinhos são o tema mais apreciado pelos editores e leitores de fanzines. Contribui para isso, certamente, o fato de o suporte dos fanzines, a revista impressa, ser o mesmo dos quadrinhos, tornando o fanzine ao mesmo tempo veículo para a reflexão sobre a arte e para a publicação dos experimentos artísticos. Dentro dessa categoria de fanzines encontram-se várias divisões, com publicações dedicadas a personagens e autores, a estúdios e grupos de produção, a gêneros e épocas. São notórios os fanzines dedicados ao universo dos super-heróis; os de nostalgia dos quadrinhos, voltados aos personagens clássicos da "época de ouro" dos quadrinhos; os de ficção científica; de faroeste, além dos que promovem o lançamento dos jovens quadrinistas. 
Roberto Benjamin (2000, p.17), ao abordar a Folkcomunicação no contexto da comunicação de massa, realça "a importância da comunicação interpessoal e grupal - inclusive pelos seus aspectos de mediação - tanto entre a população de cultura folk, como nos demais segmentos da sociedade". Essa comunicação interpessoal é, sem dúvida, uma das maiores motivações dos fanzines, que privilegiam a troca de informações entre os fãs, seja por intermédio da seção de cartas e colaborações com artigos, críticas, resenhas e quadrinhos, seja pelo contato direto com outros fãs.

Nos fanzines, os fãs se identificam num universo comum, saem do isolamento, encontram o terreno adequado para expressar suas paixões, se fortalecem como participantes de um grupo. Não só pelo aspecto de comunhão comunitária, nessas pequenas publicações os leitores e editores estimulam o olhar investigativo e crítico enquanto exercitam sua liberdade de expressão. Grandes debates e polêmicas acontecem nos fanzines, acrescentando elementos cognitivos e promovendo análises construtivas para o resgate e desenvolvimento de sua arte.

Dentro da perspectiva de comunicação de grupo, os editores e leitores dos fanzines desenvolvem linguagens comuns próprias ao grupo do qual procedem. Dessa forma, os fãs de quadrinhos possuem uma linguagem que se coaduna com seu grupo, assim como os fãs de rock utilizam jargões próprios dos apreciadores desse gênero musical. Essa linguagem comum vai além da expressão textual, chegando a demarcar de forma inconfundível o aspecto gráfico dos fanzines.

Numa classificação genérica, é comum a utilização de certos termos que unificam os vários grupos em torno da produção dos fanzines. O próprio termo fanzine é um neologismo formado pela contração de fanatic e magazine, do inglês, de onde derivaram zine, como abreviatura do termo; zinar, para a ação de se fazer o fanzine; zineiro ou fanzineiro, para o sujeito da ação; fanzinagem e fanedio, como a atividade de edição dos fanzines. Por analogia, uma fanzinoteca vem a ser uma biblioteca de fanzines.

Esses termos que permeiam os grupos de fãs aproximam-se das gírias, próprias de uma linguagem tribal e de uma expressão folclórica, ou seja, de identidade e manifestação espontânea de determinado meio cultural. Por pertencer a grupos relativamente 
isolados da sociedade, todos esses neologismos são reconhecidos de forma familiar por seus membros, mas não são imediatamente absorvidos pela cultura oficial. Apesar de o termo fanzine ter se difundido nos últimos anos particularmente na mídia, ele só agora começa a figurar em alguns dicionários e enciclopédias.

Numa aproximação com a produção de imprensa popular e outros gêneros de publicações, a exemplo dos folhetos de cordel, podemos afirmar que os fanzines fazem parte do que denominamos de Folkcomunicação, como o define Luiz Beltrão: "é o processo de intercâmbio de informações e manifestações de opiniões, idéias e atitudes de massa através de agentes e meios ligados direta ou indiretamente ao folclore" (Beltrão apus Benjamin, 2000, p.12).

É certo que os fanzines, com suas pequenas tiragens quase confidenciais, que muitas vezes não ultrapassam os 50 exemplares, não podem ser considerados um meio de massa, mas identificamos com clareza nesses veículos um forte processo de intercâmbio de informações, com destaque para a expressão da crítica e da opinião. Os fanzines têm na reflexão sua força, gerando debates entre os leitores e mesmo, em seu conjunto, interferindo nas publicações do mercado.

Por outro lado, o próprio Beltrão viria ampliar o conceito de Folkcomunicação para além das amarras da definição de folclore adotada de forma oficiosa no país. Inicialmente, ele identificava a Folkcomunicação como sendo a expressão apenas de grupos marginalizados cultural e geograficamente: "Hoje pensamos que as pesquisas se devem estender a outros setores excluídos, sem acesso aos mass media, pela sua posição filosófica e ideológica contrária as normas culturais dominantes, setores que se poderiam classificar de contraculturais" (BELTRÃO, 2000, p.13).

Essa nova definição, mais abrangente, afinal contempla os fanzines em vários aspectos de sua produção. Os fanzines são não só veículos de aficionados, mas também de grupos que não possuem acesso à grande imprensa. A divulgação das novas bandas de rock é feita particularmente por intermédio dos fanzines. Os novos autores de poesias e histórias em quadrinhos têm nos fanzines o espaço para publicação de sua obra, visto que não se tem veículos do mercado que contemplem de forma adequada o fluxo da produção dos autores nacionais, muito menos as obras dos novos artistas. 
A concentração da indústria cultural, em particular das grandes editoras no eixo Rio de Janeiro/São Paulo é mais um agravante para a veiculação de expressões regionais. Os fanzines são, pois, um produto de grupos marginalizados cultural e geograficamente, bem como porta-vozes de um tipo de cultura que denominamos genericamente de underground, contracultural ou independente.

\section{A tecnologia a favor dos fanzines}

Até o final da década de 1980 o fanzine foi concebido para ser um veículo impresso, ocupando um espaço paralelo às publicações do mercado. Talvez não fosse o caso de se falar numa imprensa alternativa, como observa Edgard Guimarães (2005), editor do fanzine QI, visto que o fanzine não se configura como uma
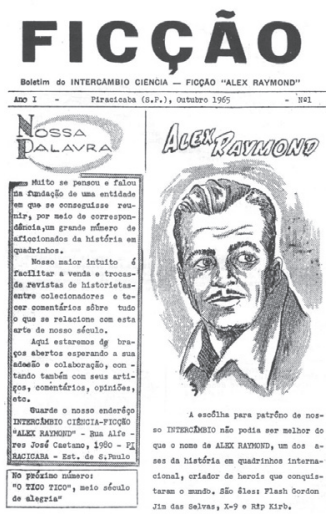

Figura 1 - Fic o, o primeiro fanzine brasileiro alternativa mercadológica. Pelo seu caráter amador, o fanzine estaria mais para uma cultura independente, livre das amarras do mercado, da imposição das grandes tiragens, da linguagem consensual para um público genérico.

O fanzine é um veículo de comunicação dirigida, que tem as dimensões do universo de seu público. Como na maioria das vezes os fanzines se identificam nas especificidades, é comum lidar-se com públicos reduzidos da mesma forma que proliferam indefinidamente os títulos e abordagens dessas publicações.

No início, para a edição dos fanzines, foram utilizados os meio rudimentares de reprodução que viabilizassem as pequenas tiragens, tendo em vista a adequação dos custos. O mimeógrafo a álcool e à tinta foram os instrumentos para as primeiras publicações, a exemplo de Fico, o primeiro fanzine brasileiro, lançado por Edson Rontani em Piracicaba, em outubro de 1965.

Com o desenvolvimento das fotocopiadoras e o barateamento das cópias, tornou-se viável a edição de fanzine por esse processo, desde a produção, com reduções e ampliações de originais 
datilografados e imagens, até a reprodução, com as cópias. Este instrumento trouxe um grande desenvolvimento aos fanzines pela qualidade de reprodução gráfica, incluindo amplamente as ilustrações. O salto tecnológico com a popularização das fotocopiadoras favoreceu a propagação dos fanzines de quadrinhos, que faziam as vezes de revistas/portfólios e revistas especializadas no gênero, com ensaios, críticas e matérias noticiosas.

A possibilidade de reprodução das artes gráficas, a exemplo dos quadrinhos, estimulou o surgimento de inúmeros autores por todo o país e com eles vieram seus fanzines. Ainda que o objetivo da maioria dos quadrinistas fosse chegar ao mercado editorial, não era mais necessário esperar uma chance remota para mostrar o trabalho. Os fanzines ocuparam o espaço, relegado pelas editoras comerciais, de veículo promotor dos novos talentos, estimulando o aparecimento de sucessivas gerações de quadrinistas.

A importância dos fanzines dá-se também pelo papel de vanguarda cultural que eles engendram. É nos fanzines onde são experimentadas as novas linguagens, o padrão gráfico inovador, as ousadias conceituais. Não raro, o meio empresarial vai buscar nos fanzines a renovação estética para certos públicos identificados com novas linguagens. Os fanzines, enquanto manifestação espontânea e democrática de grupos, muitas vezes formados por jovens, trazem a legitimação das linguagens populares nem sempre facilmente percebidas pelos meios empresariais.

O melhor exemplo para ilustrar essa postura, é a difusão maciça de alguns nomes dos cartuns nacionais. Os maiores autores de tiras, charges e cartuns veiculados nos jornais de circulação nacional da atualidade vieram do meio dos fanzines e publicações alternativas. Uma quantidade enorme de novos quadrinistas é influenciada por Henfil, Angeli, Ziraldo, Laerte, Paulo Caruso e Jaguar, para citar apenas alguns dos autores consagrados. Dessa forma, começamos a assistir o reconhecimento do trabalho de Marcatti, Edgar Franco, Wellington Srbek e Cedraz como autores de obras personalizadas, além de jovens autores de nossa arte seqüencial (os quadrinhos).

Do mesmo modo que os fanzines podem servir como alavanca para a profissionalização, eles têm favorecido o surgimento de pequenas editoras independentes. O público dessas editoras é o mesmo dos fanzines, acrescido de outras camadas simpáticas a produtos 
diferenciados do mercado. Um dos fatores que tem contribuído para o surgimento dessas editoras e para a concepção de um produto cultural bem

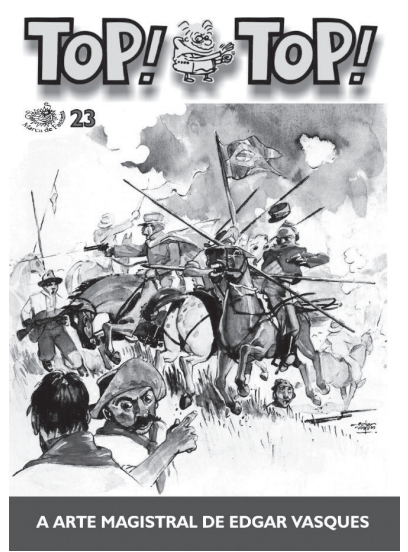

Figura 2 - Fanzine Top! top! mais acabado é, sem dúvida, a revolução tecnológica trazida pela informática.

O folclore e a cultura popular não devem ser encarados como uma cultura estática, imutável. Ela vem se adaptando às transformações da sociedade, incorporando elementos da mitologia urbana, das mídias e das novas tecnologias. Numa alusão à produção dos folhetos de cordel, Luiz Beltrão, citado por Roberto Benjamin, afirma que justamente a mais nova apropriação tecnológica ocorreu com relação à informática.

\section{O poeta po-}

pular José Honório produz seus versos em um computador. A sua opção pela informática nada tem de romântica. Foi uma escolha tecnológica e econômica. As gráficas existentes na cidade onde reside (Timbaúba-PE), desde as primitivas de caixas de tipo, às que operam off-set, somente recebem encomendas de tiragens acima das possibilidades de mercado, para os cordéis do poeta. Utilizando o computador, José Honório imprime o número de folhetos que considera possível vender de imediato e guarda os mesmos na memória eletrônica, realizando novas tira-

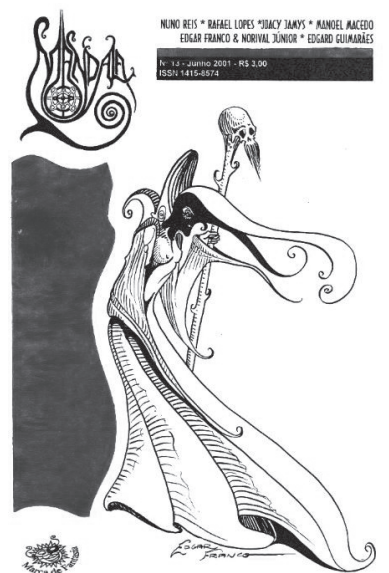

Figura 3 - Fanzine Mandala gens na medida em que as pequenas edições se esgotam (BENJAMIN, 2000, p.19-20).

De forma coincidente, esta é a mesma estratégia adotada pela editora Marca de Fantasia, de João Pessoa, PB. Por esta editora independente são feitas edições seqüenciais de fanzines, revistas e 


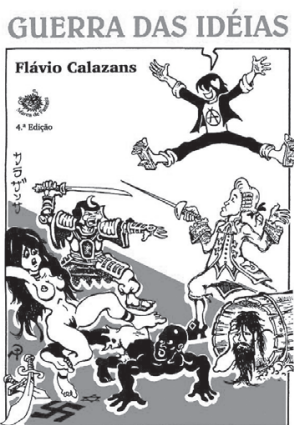

Figura 4 - Fanzine Guerradas /dias de Flávio Calazans

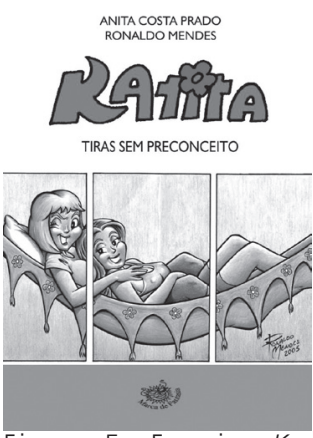

Figura 5 - Fanzine Katita: tiras sem preconceito de Anita C. Prado e Ronaldo Mendes

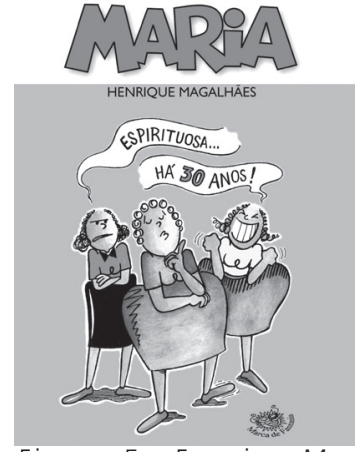

Figura 5 - Fanzine $M a$ ria de Henrique MagaIhães

livros de tiras (Top! Top!; Mandala, Quiosque; e a coleção "Das tiras, coração", respectivamente), além de álbuns de histórias em quadrinhos e livros teóricos sobre cultura pop. Cada publicação tem tiragem inicial de 50 exemplares, para uma projeção de 200 exemplares; ao esgotar-se essa primeira edição, outra tiragem é produzida, dando seqüência à difusão da obra. Dessa forma, o álbum Guerra das Idias, de Flávio Calazans, que está na quarta edição ampliada, conta já com 360 exemplares, o álbum de tiras Katita: tiras sem preconceito, de Anita Costa Prado e Ronaldo Mendes já teve a primeira tiragem esgotada e Maria, de Henrique Magalhães, foi publicado com 800 exemplares.

Sem dúvida, o avanço dos recursos tecnológicos transformou alguns fanzines em publicações compatíveis com boa parte das publicações do mercado. Com o computador, o visual dos fanzines tornou-se mais limpo, livre das imperfeições dos tipos datilográficos, dos riscos de canetas e colagens de originais.

É certo que essas transformações não foram aceitas com tranqüilidade por uma parte dos editores, que viam no acesso fácil à tecnologia o fim da pureza artesanal dos fanzines. Para eles, a verdadeira linguagem dos fanzines deveria ser aquela suja, que atestasse o labor artesanal, a presença da alma e do suor do editor, com suas imperfeições e máculas, próprias da expressão humana mais autêntica.

Mas o canto sedutor da tecnologia soou mais alto e de forma 
irreversível. Atualmente já podemos ver fanzines com qualidade gráfica excepcional, com utilização de cores nas capas impressas em offset ou impressão à laser, e com os requintes dos melhores

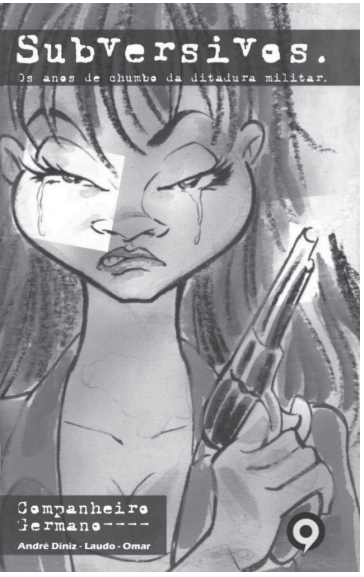

Figura 6 - Revista Subver sivos

programas gráficos, acessíveis em qualquer computador. Essa evolução dos fanzines e demais publicações independentes (revistas, álbuns, livros), faz-nos pensar na possibilidade da formação de um mercado paralelo, criando um filão até então inexistente no meio editorial.

Já existem alguns núcleos de produção que têm utilizado as novas tecnologias bem como as leis de incentivo à cultura estaduais e municipais para a edição de excelentes publicações. Podemos citar a editora Nona Arte, de André Diniz, do Rio de Janeiro, que vem desenvolvendo um trabalho excepcional na edição de revistas independentes, abrindo espaço não só para sua produção como para a de outros autores representativos dos quadrinhos brasileiros. A série Subversivos, editada por ele, reconta a história recente do Brasil sob o regime militar a partir da visão dos reprimidos, das organizações clandestinas que visavam uma transformação radical do país. Esta é uma visão dos perdedores, que em geral não entra nos anais da história.

Da mesma forma, Wellington Srbek, em Belo Horizonte, tem aproveitado o incentivo estatal para a publicação de revistas e álbuns com acabamento gráfico profissional e conteúdo também voltado


Figura 6 - Estrias Gerais de Wellington Srbek para elementos da cultura brasileira. São visões de histórias e lendas e mesmo da ficção extraordinária dos super-heróis que fazem uma ligação entre a cultura popular e a erudita. As revistas e álbuns são produzidos dentro do circuito dos fanzines, mas estão abertos a outros públicos, que venham somar à valorização de uma arte genuinamente brasileira. 
Curioso é que trabalhos tão criativos e autorais não tenham espaço nas editoras comerciais. A busca do lucro fácil, das fórmulas feitas, da importação de modelos estrangeiros da cultura de massa como diretrizes do mercado fazem com que as expressões mais autênticas de nosso povo sejam menosprezadas, cabendo à resistência de seus criadores, nesse caso à auto-edição ou o estabelecimento de circuitos independentes, o registro de uma cultura com caráter nacional.

\section{Conclusão}

Os fanzines de quadrinhos no Brasil representam a resistência dos quadrinhos brasileiros frente ao descaso das grandes editoras e a invasão dos quadrinhos estrangeiros. A importância dos fanzines se configura não só pela difusão e renovação dos quadrinhos no Brasil, mas também por contribuírem para a formação do público e criação de um espaço essencial de discussão e avaliação dos quadrinhos como expressão artística.

A partir da década de 1960, com o surgimento do primeiro fanzine brasileiro, é possível notar uma sensível evolução da visão crítica dos leitores e do posicionamento proativo dos novos autores. Foi nos fanzines que esses agentes culturais e o público recolheram elementos para a formação de uma visão mais ampla sobre os quadrinhos como fruto da indústria cultural, mas também como veículo extraordinário de reflexão, que extrapola o universo de seus renomados heróis.

Inicialmente como boletins rudimentares (mimeografados) de fãs-clubes ou aficionados, os fanzines tornaram-se, com o desenvolvimento tecnológico e popularização dos meios de impressão, publicações cada vez mais sofisticadas, aproximando-se do requinte das publicações do mercado. No entanto, mantêm seu caráter contestador e veículo de integração de grupos culturalmente marginalizados.

Essas novas publicações independentes têm tomado fôlego nos últimos anos, conquistando um público curioso e exigente, que vai buscar nas livrarias especializadas e não nas bancas de revistas o 
produto para sua apreciação. A resposta a esse público encontrase na evolução gráfica das publicações e no aprimoramento do conteúdo, onde se procura refinar a elaboração dos argumentos e uma concepção mais sólida dos personagens.

\section{Referências}

Beltrão, Luiz. Folkcomunicao: a comunicação dos marginalizados. São Paulo: Cortez, 1980.

Benjamin, Roberto. Folkcomunicao no contexto de massa. João Pessoa: Editora Universitária/UFPB, 2000, p. 17.

Bibe-Luyten, Sonia M. (organizadora). Histrias em Quadrinhos: Leitura crítica. 2ª ed. São Paulo: Edições Paulinas, 1985.

Bibe-Luyten, Sonia M. Coleção Primeiros Passos, 144. O que Histria em Quadrinhos. São Paulo: Brasiliense, 1985.

Calazans, Flávio Mário de Alcântara (organizador). As histrias em quadrinhos no Brasil: teoria e prática. Coleção GT Intercom no 7. São Paulo: 1997.

Guimarães, Edgard. Fanzine. Coleção Quiosque n², $3^{\text {a }}$ ed. João Pessoa: Marca de Fantasia, 2005.

Magalhães, Henrique. O que fanzine. Coleção Primeiros Passos, 283. São Paulo: Brasiliense, 1993.

Magalhães, Henrique. O rebulio apaixonante dos fanzines. João Pessoa: Marca de Fantasia/Ed. Universitária UFPB, 2003.

Morin, Edgar. Les stars. France: Editions du Seuil, 1972, p. 68.

Pinheiro, Helder \& Lúcio, Ana Cristina Marinho. Cordel na sala de aula. Coleção literatura e ensino, 2. São Paulo: Duas Cidades, 2001.

Ribeiro, Maria de Lourdes Borges. Folclore. Biblioteca Educação é Cultura. Rio de Janeiro: Bloch: Fename, 1980.

Semião, Antônio Éder et alli. Tudo que voc sempre quis saber sobre quadrinhos mas sua mame relutava em Ihe responder Curitiba: 
Edição do autor, abril de 1996.

\section{Artigos}

Andraus, Gazy. Tyli-Tyli: A revista de quadrinhos filosficos do Brasil. In Calazans, Flávio Mário de Alcântara (organizador). As histrias em quadrinhos no Brasil: teoria e prática. Coleção GT Intercom no 7. São Paulo: 1997, p. 81-91.

Franco, Edgar. Panorama dos quadrinhos subterrneos no Brasil. In Calazans, Flávio Mário de Alcântara (organizador). As histrias em quadrinhos no Brasil: teoria e prática. Coleção GT Intercom no 7. São Paulo: 1997, p.51-65.

Guimarães, Edgard. A questo da produo, divulgao e distribuio de edies independentes. In Calazans, Flávio Mário de Alcântara (organizador). As histrias em quadrinhos no Brasil: teoria e prática. Coleção GT Intercom no 7. São Paulo: 1997, p.66-80. 
Fanzine: comunicação popular e resitência cultural

Henrique Magalhães

Professor Dr. da Universidade Federal da Paraíba, UFPB

Mestre em Ciências da Comunicação pela Universidade de São Paulo. Doutor em Sociologia pela Universidade Paris 7, França. Professor do Departamento de Comunicação e Turismo e do Mestrado em Comunicação da UFPB. Faz pesquisa e extensão na área de cultura e imprensa alternativa. Criador e editor da editora Marca de Fantasia e da Gibiteca Henfil, de João Pessoa. henriquemais@gmail.com 